\title{
Impact of Educational Self-Efficacy Enhancement Program on Quality of Life, Pain Management, Self- Efficiency Behaviors, and Its Impact of Satisfaction among Adult Diabetic Patients with Peripheral Neuropathy Pain
}

Jawad Ahmad Abu-Shennar ( $\sim$ jawad_0799@yahoo.com )

Near East University

Nurhan Bayraktar

Near East University: Yakin Dogu Universitesi

\section{Research}

Keywords: Diabetic peripheral neuropathy pain, Quality of life, Self-efficacy, Pain

Posted Date: November 12th, 2020

DOI: https://doi.org/10.21203/rs.3.rs-103579/v1

License: (c) (1) This work is licensed under a Creative Commons Attribution 4.0 International License. Read Full License 


\section{Abstract}

\section{Aims:}

This study aims to investigate the impact of the educational self-efficacy enhancement program on quality of life, pain management, self-efficiency behaviors, and its impact satisfaction among adult diabetic patients with peripheral neuropathy pain.

\section{Materials and methods:}

This randomized controlled study was conducted at the Jordanian Ministry of Health. during the period from October - March 2020 with 72 adult diabetic patients with peripheral neuropathy pain, after the ethical approval. Study group participants have implemented an educational self-efficacy enhancement program. Demographic data from, Diabetes Self-Efficacy Scale, Quality of Life Questionnaire (EQ-5D), Pain Intensity Scale, and Patient Satisfaction Questionnaire were used in data collection.

Results: This study found that the self-efficacy enhancement program had a significantly positive impact on diabetic peripheral neuropathy pain patients' QoL, pain levels, self-efficiency behaviors, and satisfaction.

Conclusion: It is crucial to improve their self-efficacy behaviors and modification of lifestyle and behavioral changes such as appropriate diet, exercise, reduce weight and encouragement stop smoking, and regularly visit treating physicians.

\section{Introduction}

Diabetic peripheral neuropathy pain disease (DPNP) is one of the most common and complex chronic diseases [13]. Defined by the American pain society (APS), DPNP is an unpleasant sensory and emotional experience associated with acute or potential tissue damage or described in terms of such damage. It involves characterized by burning, aching, or shooting in nature [4]. A cohort study in the UK showed the estimated incidence of DPNP at 15.3 cases per 100,000 person-years in the primary care population in 2002, increasing to 27.2 cases per 100,000 people in 2005 [5]. Roughly, more than $11 \%$ of patients with DPN are suffering from DPNP in the world [6].

DPNP is reported to usually interfere with daily living activities, mood, work, mobility, and social relations. Additionally, impaired patients' health could have a negative impact on the patients' quality of life (QoL). DPNP causes higher societal and health care costs compared to diabetes but without neuropathic pain [6]. Glycemic blood level plays a crucial role in the onset and development of DPNP and although drug therapy and rehabilitation cause relative improvements, control of hemoglobin glycosylated $(\mathrm{HbA} 1 \mathrm{c})$ are very important in the prevention of complications disease [7-10].

Self-care behaviors of the patients with DPNP can alleviate severe symptoms and enhance clinical outcomes, quality of life, and pain management, also reduce further hospitalizations $[11-12,10,8,13,7,14-15]$. Several factors can impact the self-care of patients including the behavior of an individual and self-efficacy [16-19]. Selfefficacy reflected the main principle of social cognitive the theory was originally proposed through Bandura. Selfefficacy behaviors are described as one's belief in her/ his capabilities to complete expect and tasks to reach purposes [20]. Furthermore, it should be noted that education performs a crucial role in improving and enhancing the function of individual behavior. 
In view of the developing prevalence of DPNP and the role that educational self-efficacy enhancement program plays in self-care enhancement, this research was performed to investigate the impact of educational self-efficacy enhancement program on quality of life, pain management, self-efficiency behaviors, and its impact of satisfaction among adult diabetic patients with DPNP.

\section{Materials And Methods Study design}

The randomized controlled study design was carried out in the current study.

\section{Setting and sample}

The study was conducted at the Jordanian Ministry of Health. The three hospitals are integrated under the name of the Jordan Ministry of Health. The researcher chose this setting because it receives referrals from all medical sectors in different parts of Jordan. The target population for this study was all voluntary adult diabetic patients with DPNP who visited the Jordanian Ministry of Health, during the period from the ${ }^{14 \text { th }}$ of October 2019 to the ${ }^{14 t h}$ of March 2020, and who are $\geq 18$ years of age having regular follow up in the hospitals for at least six months were included in the study. The total sample size was 72 adult diabetic patients with DPNP, 36 subjects in each control and study groups, were recruited.

\section{Study instruments}

An assessment tool package was used. This package consists of five parts. The first part was developed by the researchers and consisted of the demographic data from the subjects who met the inclusion criteria.

The second part was the Diabetes Self-Efficacy Scale (DSES) for diabetes patients was introduced by the Stanford Self-Management Resource Center (SMRC) in 2009, which includes eight items rated along a five-point Likert scale (from $1=$ to corresponded to never self-efficacy to $5=$ to very good self-efficacy) [21]. Scores ranged from 0 to 10 . Higher scores correlated with better self-care. The validity and reliability were performed by Al-Amer et.al (2016) in Jordan and were taken into consideration. The DSES was translated into Arabic, with the Cronbach's alpha of the revised scale was 0.81 [22].

The third part is the quality of life questionnaire entitled EQ-5D [23]. This standardized instrument includes four domains that measure the QoL: mobility, self-care, usual activities, and anxiety/depression. The overall score was as 1: perfect health and 0: dead [23]. The EQ-5D has been translated by the researcher and checked by two professional academic instructors (Dr. Maysoon Abdalrahim and Dr. Ruqayya Zeilani) in the field of nursing to ensure the consistency of inquiring the information while interviewing the patients. The Jordanian reliability and validity studies of the EQ-5D was performed by Abu-Shennar et.al. in 2020. The Cronbach's alpha of the revised scale was 0.88 [24].

The fourth part is the researchers have used pain intensity scales. Each patient was asked to point to the number that represents the intensity of his current pain experience. According to our authors in the current study, responses were rated on a scale of 0 to 10 where $\leq 3$ indicating mild pain, 4-7 indicating moderate pain, and 8-10 indicating severe pain. 
Finally, the researcher has used the patient satisfaction questionnaire for evaluation to measure and assess the education tools and program efficiency and effectiveness. The scale consists of ten items, which was prepared by researchers. According to the authors, responses were rated on a scale of one to five where 1 corresponded to never, 2 to low, 3 to moderate, 4 to good, and 5 to very good to determine whether further training is required during the education program in sessions. A pilot study was performed among Jordanian patients having DPNP at the Jordanian Ministry of Health for clarity of patient satisfaction questionnaire. According to the results of the pilot study, necessary revisions were made on the questionnaire.

\section{Educational tools and program}

The educational tools and programs are a specially-designed instrument for adult diabetic patients with peripheral neuropathy pain. The educational tools including a booklet, demonstrative pictures, videotapes were prepared and the programs were organized. This program was prepared by the researchers based on the relevant literature [11$12,10,2-3,25]$ and involved four sessions of rehabilitation and self-efficacy enhancement for each patient group. After all educational tools and program developed three specialized persons (three professionals: one with a Ph.D. in nursing, one in medicine, and Ph.D.in pharmacy \& toxicology specializes) were review and approve about these tools, which was followed content:

- Information about diabetes mellitus and DPNP.

- Diabetes complications; prevention of through self-care.

- Compliance with medication, diet, and exercises.

- Self-monitoring and regular follow-up.

\section{Implementation}

The intervention program was implemented for the trial and control group during the period between the ${ }^{14 \text { th }}$ of October 2019 to the ${ }^{14 \text { th }}$ of March 2020:

\section{Study group:}

- A face to face structured interview using Descriptive Data Questionnaire, Quality of Life Questionnaire (EQ-5D), Numeric Pain Rating Scale (NRS), and Self-Efficacy for Diabetes Questionnaire (DSES) were performed while waiting for patients turn in the clinic waiting room.

- Educational sessions were performed. The intervention is consisting of small groups (8-10 patients) of structured educational sessions on the enhancement programs on the quality of life of adult diabetic patients with DPNP. The educational sessions were one hour to 90 minutes. The training booklet and a PowerPoint presentation were performed for the participants.

- A review was repeated in this phase of the mentioned material an educational booklet was handed to the trial group which comprised the material presented in the four-session period.

- The evaluation of the self-efficacy training program on DPNP among adult diabetic patients is carried out three months after the education enhancement program. Participants have completed the Quality of Life Questionnaire (EQ-5D), Numeric Pain Rating Scale (NRS), Self-Efficacy for Diabetes Questionnaire (DSES), and Patient Satisfaction Questionnaire were implemented.

\section{Control Group:}


A face to face structured interview using Descriptive Data Questionnaire, Quality of Life Questionnaire (EQ-5D), Numeric Pain Rating Scale (NRS), and Self-Efficacy for Diabetes Questionnaire (DSES) were performed while waiting for patients turn in the clinic waiting room.

\section{Statistical analysis}

Statistical analysis was carried out using the Statistical Package for Social Sciences (SPSS, version 25).

Descriptive statistics obtained such as mean and stander deviation (SD) values for continuous and proportions for categorical variables. Paired-Samples T-Test also was used to perform the comparisons. For categorical variables for each set of data, was used Frequency and One-Sample T-Test analysis. A P-value of less than 0.05 considered statistically significant.

\section{Ethical consideration}

Data were collected after approval by the ethical committee in the Jordanian Ministry of Health and Near East University (N.E.U). We have got approval from SMRC to apply of the DSES as all right was reserved, and reproduced. The data was used only for scientific inquiries. Since the study was based on data obtained from medical records and structured questionnaires, no harm to adult diabetic patients with DPNP was expected. Verbal consent was taken by those eligible participate and they were assured about the confidentiality of information.

\section{Results}

In this randomized controlled study, the results of the descriptive characteristics of the participants showed that the mean of the ages was 66.3 years of the study group and 60.9 years of the control group. More than half of the participants were male in both groups (study group: $75 \%$, control group: $63.9 \%$ ). $33.3 \%$ of the study group participants and $38.9 \%$ of the control group participants had a bachelor's degree or higher. All of the patients in both groups were non-compliant to physical activity and reported non-adherence to the diet regimen. Also, $38.9 \%$ of the study group participants and $30.6 \%$ of the control group participants were current smokers. The mean body mass index (BMI) $(\mathrm{Kg} / \mathrm{m} 2)$ was 37.59 among the study group participants and 39.44 among the control group participants. The mean duration of diabetes was 12.4 years in the study group and 9.1 years in the control group. There was a statistically significant difference between the study group and the control group in terms of duration of diabetes and age $(p=0.000, P<0.01)$.

In the pre-educational self-efficacy evaluation of the study and control group patients, results showed that the mean self-efficacy behaviors score for the participants included in the study group was 1.43, while control groups were 1.78, and this difference was found significant statistically $(P<0.01)$. There were low self-efficacy behaviors scores for both groups in pre-educational evaluation [Table 1]. The self-efficacy mean score of the study group participants was increased to 3.46 ( \pm 0.59$)$ in post-educational evaluation, while the score was $1.43( \pm 0.16)$ in preeducational evaluation, and this difference was found significant statistically [Table 2].

Regarding the pain levels of the patients in pre-educational evaluation, results showed that the mean scores of the participants were 7.83 for the control group, while 6.5 for the study group, and this difference was found significant statistically $(P<0.01)$ [Table 3]. The mean pain score of the study group was lower in post-educational evaluation (5.1) which was significant statistically $(P<0.01)$ [Table 4].

Findings of the study regarding the quality of life showed that, in pre-educational evaluation, the EQ-5D means score was 4.11 for the study group, while the mean score was 3.67 for the control group, and this difference was 
found significant statistically $(\mathrm{P}<0.01)$ [Table 3]. The EQ-5D mean score of the study group participants was lowered to 2.07 in post-educational evaluation, while the score was 4.11 ( \pm 0.67 ) in pre-educational. Because of the reverse evaluation of the items, this lower value of QoL in post-educational evaluation shows positive improvement in life quality, with $P$-value, which was significant $(P<0.01)$ [Table 4].

Finally, patient satisfaction means a score of the study group participants was $4.33( \pm 0.67)$, and this result shows a high level of satisfaction from educational intervention [Table 5].

\section{Discussion}

In this randomized controlled research that was performed to investigate the impact of educational self-efficacy enhancement program on quality of life, pain management, self-efficiency behaviors, and satisfaction among adult diabetic patients with DPNP, results showed the effectiveness of the educational self-efficacy enhancement program.

Self-efficacy

In a pre-educational evaluation of the self-efficacy behaviors evaluation levels of the patients, results showed that the mean self-efficacy behaviors scores for both group participants were showing low levels. These results of this study were concordant with those from other epidemiological studies [11-12, 10, 8, 13, 7, 14-15], where patients with DM had significantly lower self-efficacy behaviors than those without DM. This might be attributed to the that was associated with lower levels of self-efficacy behaviors by poor self-management skills practicing, and lower knowledge of the patients about the disease with uncontrol of the complications, which leads to negative feedback was frequently implemented among patients with DPNP.

In our study, the study group participants who attended the educational self-efficacy enhancement program reported a positive enhanced self-efficacy behavior by comparing the pretest and posttest mean. The essential findings of this study suggest the importance of incorporating self-efficacy enhancing interventions in diabetes self-efficacy (DSE) programs, emphasizing the requirement to build confidence specific to a given selfmanagement behavior as a portion of the health care providers communication or as a component of an educational, counseling, and skill-building program that can enhance the likelihood of maintaining the preferred outcomes of DPNP. Diabetes nurse educators and other health care providers need to develop effective methods for promoting self-management among adult Jordanian individuals. Recent results analyses also have reported that in the follow-up intervention, health-related improvements gained from self-management programs. The selfmanagement methods effectively increase participants' knowledge, symptom self-management, other selfmanagement behavior such as weight control, self-efficacy, testing blood glucose, and aspects of health status management significantly [26]. Many clinical studies confirm that the effect of the educational program selfefficacy enhancing interventions in DSE programs among T2DM patients [11-12, 10, 8, 13, 7, 14-15].

Pain

In a pre-educational evaluation of the pain levels of the patients, results showed that the majority of the participants in both groups were having different intensities of pain ranging from moderate to severe. According to a cohort study in the U.K. study by Abbott et al. (2011), the results showed that the painful symptoms occurred in $26 \%$ of patients without neuropathy and $60 \%$ of patients with severe neuropathy [27]. According to pain intensity, $61 \%$ of patients had a pain of moderate-intensity in a cross-sectional study was done by Van Acker et al (2009) 
[28]. While a study from the same region was conducted in French by Bouhassiraet.al (2013) using the NRS showed that $76.2 \%$ of patients are having a pain of moderate to severe intensity [29]. The difference in the reported pain neuropathic characteristics from all over the world can be related to different populations of the studies and the different screening tools that are used to assess DPNP.

In our study, the study group participants who attended the educational self-efficacy enhancement program reported better management pain as perceived by comparing the pretest and posttest means showing improvement after exposure to the educational program. Congruent to the results of the majority of the studies found that control $\mathrm{HbA} 1 \mathrm{c} \%$, dietary regimen, foot care, and exercise and lifestyle behavior does affect their good management of pain in patients with diabetes multiuse [30-31,29-28].

Quality of life

In a pre-educational evaluation, results showed that the quality of life means the scores were showing a low QoL level. Also, the results of the study showed that most of the participants who have DPNP reported have a problem in mobility, self-care, usual activity, discomfort, and anxious or depressed. These results of this study were concordant with those from other epidemiological studies, where patients with DPNP had significantly lower QoL than those without DPNP. For example, according to a study by Davies et al. (2006), they found that patients who developed DPNP had poorer quality of life [30]. Similar results were found in a study by Van Acker et al (2009), the results revealed that patients with DPNP were higher likely to report problems physical activities and mental alterations than those without DPNP, which may account for their lower QOL scores [28]. In a more recent study conducted in France, the results showed that DPNP was associated with disturbances in sleep, higher anxiety levels, and depression [29]. Another recent study that agrees with the results of our study was performed in South Africa. In this study, the results suggested that DPNP has a negative impact on QoL. [31].

The findings of this study found that the study group participants who attended the educational self-efficacy enhancement program reported a positive impact on QoL. This finding was consistent with the relevant studies [32-38]. While data obtained from a study in Saudi Arabia on contrary to our study, this was not significantly associated with the effect of the educational program and QOL among diabetic patients with T2DM [39]. Similarly, a study was done in Taiwan failed to show any significant association between the effect of the educational program and QOL among T2DM [40]. However, the variation in magnitude between these findings and others may be attributed to either the differences in sample size or the characteristics of the study participants.

Patient satisfaction

Patient satisfaction means a score of the study group participants showed a high level of satisfaction from educational intervention. Numerous clinical studies confirm that the effect of the educational program self-efficacy enhancing interventions in high levels of satisfaction among diabetic patients [16-19]. Conscientious steps to improve patient satisfaction and engagement are therefore vital for improving the quality of patient care and conveying the important message that healthcare providers are respected and valued as persons.

\section{Conclusion And Recommendations}

There are some limitations that may be recognized in relation to the conduction of this study. Although the focus of this study was to investigate PDNP among adult patients, the data collection lacks identifying if patients were taking pain pharmacological and non-pharmacological therapies. 
This study found that the self-efficacy enhancement program had a positive impact on DPNP patients' QoL, pain levels, self-efficiency behaviors, and satisfaction. Consequently, in order to promote self-care behaviors of patients, it is crucial to improve their self-efficacy behaviors and modification of lifestyle and behavioral changes such as appropriate diet, exercise, reduce weight and encouragement stop smoking, and regularly visit treating physicians during a nursing career. Future researches are recommended to include patients from different health care sectors in Jordan and other health care facilities.

\section{Abbreviations}

T2DM

Type 2Diabetes Mellitus.

DPNP

Diabetic Peripheral Neuropathic Pain.

QOL

Quality of life.

NSS

Neuropathy symptom score.

DSES

Diabetes Self Efficacy Scale

BMI

Body Mass Index.

HbA1c

Hemoglobin Glycosylated.

SPSS

Statistical Package for Social Science.

SD

Standard Deviation.

APS

American Pain Society.

SMRC

Stanford Self-Management Resource Center

NRS

Numeric Pain Rating Scale.

N.E.U

Near East University.

DSE

Diabetes Self-Efficacy.

\section{Declarations}

Ethical Approval Committee: Available. Ethics committee approval was received for this study from the Jordanian Ministry of Health Ethical Board (No: 8041).

Participants Inform Consent: Available 
Financial Support And Sponsorship: No financial support of this study

\section{Orcid ID No Orcid ID No}

Jawad Ahmad Abu-Shennar: 0000-0001-9958-2431.

Nurhan Bayraktar:

\section{Authors' contributions}

JAA: Study design, data collection, statistical analysis, and manuscript preparation. Responsible and accountable for the accuracy or integrity of the work

NB: Review, edit, and final approval of the manuscript.

Acknowledgment: We are grateful to extend our thanks to the Near East University, Nicosia, Cyprus, and the Jordanian Ministry of Health, Jordan, Amman for all supports in this research. We also thank all patients who take part in this research.

Conflicts of interest: There are no conflicts of interest.

Consent for Publication: Not applicable.

Availability of supporting data: Not applicable.

Funding: Not applicable.

\section{Acknowledgments}

We are grateful to extend our thanks to the Near East University, Nicosia, Cyprus, and the Jordanian Ministry of Health, Jordan, Amman for all supports in this research. We also thank all patients who take part in this research.

\section{References}

1. Fowler MJ. Microvascular and macrovascular complications of diabetes. Clinical diabetes. 2008;26(2):77-82. https://doi.org/10.2337/diaclin.26.2.77.

2. Neuropathies D. (2009). The nerve damage of diabetes. US Department of Health and Human Services.

3. Tesfaye S, Selvarajah D. Advances in the epidemiology, pathogenesis and management of diabetic peripheral neuropathy. Diab/Metab Res Rev. 2012;28:8-14. https://doi.org/10.1002/dmrr.2239.

4. Treede RD. (2018). The International Association for the Study of Pain definition of pain: as valid in 2018 as in 1979, but in need of regularly updated footnotes. Pain reports, 3(2). doi:10.1097/PR9.0000000000000643.

5. Hall GC, Morant SV, Carroll D, Gabriel ZL, McQuay HJ. An observational descriptive study of the epidemiology and treatment of neuropathic pain in a UK general population. BMC Family Practice. 2013;14(1):28. https://doi.org/10.1186/1471-2296-14-28.

6. Gilron I, Baron R, Jensen T. (2015, April). Neuropathic pain: principles of diagnosis and treatment. In Mayo Clinic Proceedings (Vol. 90, No. 4, pp. 532-545). Elsevier. https://doi.org/10.1016/j.mayocp.2015.01.018. 
7. Atak, N., Gurkan, T., \& Kose, K. (2008). The effect of education on knowledge, self-management behaviours and self-efficacy of patients with type 2 diabetes. Australian Journal of Advanced Nursing, The, 26(2), 66. Availability: <https://search.informit.com.au/documentSummary;dn=198857737071665;res=IELHEA> ISSN: $0813-0531$.

8. Al-Khawaldeh OA, Al-Hassan MA, Froelicher ES. Self-efficacy, self-management, and glycemic control in adults with type 2 diabetes mellitus. Journal of Diabetes its Complications. 2012;26(1):10-6. https://doi.org/10.1016/j.jdiacomp.2011.11.002.

9. Mohebi S, Azadbakht L, Feizi A, Sharifirad G, Kargar M. (2013). Review the key role of self-efficacy in diabetes care. Journal of education health promotion, 2. doi:10.4103/2277-9531.115827.

10. Sharoni SKA, Rahman HA, Minhat HS, Shariff-Ghazali S, Ong MHA. The effects of self-efficacy enhancing program on foot self-care behaviour of older adults with diabetes: A randomised controlled trial in an elderly care facility, Peninsular Malaysia. PloS one. 2018;13(3):e0192417. doi:10.1371/journal.pone.0192417.

11. Moein M, Aghajani M, Ajorpaz NM, Khorasanifar L. (2017). Effect of an empowerment program on selfefficacy of patients with type 2 diabetes. Iranian Red Crescent Medical Journal, 19(1).

DOI:10.5812/ircmj.29252.

12. Tan CCL, Cheng KKF, Hwang SW, Zhang N, Holroyd E, Wang W. (2018). Effect of a Diabetes Self-Efficacy Enhancing Program on Older Adults with Type 2 Diabetes: A Randomized Controlled Trial. Clin Nurs Res, 1054773818792480. https://doi.org/10.1177/1054773818792480.

13. Moriyama M, Nakano M, Kuroe Y, Nin K, Niitani M, Nakaya T. Efficacy of a self-management education program for people with type 2 diabetes: results of a 12-month trial. Japan Journal of Nursing Science. 2009;6(1):51-63. https://doi.org/10.1111/j.1742-7924.2009.00120.x.

14. Wu SC, Driver VR, Wrobel JS, Armstrong DG. (2007). Foot ulcers in the diabetic patient, prevention and treatment. Vascular health and risk management, 3(1), 65. PMID: 17583176.

15. Sarkar U, Fisher L, Schillinger D. Is self-efficacy associated with diabetes self-management across race/ethnicity and health literacy? Diabetes Care. 2006;29(4):823-9.

https://doi.org/10.2337/diacare.29.04.06.dc05-1615.

16. De Simone S, Planta A, Cicotto G. The role of job satisfaction, work engagement, self-efficacy and agentic capacities on nurses' turnover intention and patient satisfaction. Appl Nurs Res. 2018;39:130-40. https://doi.org/10.1016/j.apnr.2017.11.004.

17. Krass I, Delaney C, Glaubitz S, Kanjanarach T. Measuring patient satisfaction with diabetes disease state management services in community pharmacy. Research in Social Administrative Pharmacy. 2009;5(1):31-9. https://doi.org/10.1016/j.sapharm.2008.05.006.

18. Zanetti ML, Otero LM, Biaggi MV, Santos MAD, Péres DS, Guimarães FPDM. Satisfaction of diabetes patients under follow-up in a diabetes education program. Rev Latinoam Enferm. 2007;15(4):583-9. https://doi.org/10.1590/S0104-11692007000400010.

19. Garrett DG, Bluml BM. Patient self-management program for diabetes: first-year clinical, humanistic, and economic outcomes. Journal of the American Pharmacists Association. 2005;45(2):130-7. https://doi.org/10.1331/1544345053623492.

20. Bandura A. Self-efficacy mechanism in human agency. American psychologist. 1982;37(2):122. https://doi.org/10.1037/0003-066X.37.2.122. 
21. Lorig K, Ritter PL, Villa FJ, Armas J. (2009). Community-based peer-led diabetes self-management. The Diabetes Educator, 35(4), 641-51.

https://doi.org/10.1177/0145721709335006.https://www.selfmanagementresource.com/docs/pdfs/English__self-efficacy_diabetes.pdf.

22. Al-Amer R, Ramjan L, Glew P, Randall S, Salamonson Y. Self-efficacy, depression, and self-care activities in adult Jordanians with type 2 diabetes: the role of illness perception. Issues Ment Health Nurs.

2016;37(10):744-55. DOI:10.1080/01612840.2016.1208692. PMID:27484761.

23. EuroQol G. EuroQol-a new facility for the measurement of health-related quality of life. Health Policy. 1990;16(3):199. https://doi.org/10.1016/0168-8510(90)90421-9.

24. Abu-Shennar J, Bebis H, Bayraktar N. (2020). EQ-5D OF ADULT DIABETIC PATIENTS WITH PERIPHERAL NEUROPATHY PAIN: ARABIC VALIDITY AND RELIABILITY STUDY OF LIFE QUALITY SCALEA. In 28th Şubat-1st Mart, Kibris. 17th NÖROPATIKK AĞRI SEMPOZYUMU Conference. p. 9.

25. American Diabetes Association. (2017). 2. Classification and diagnosis of diabetes. Diabetes care, 40(Supplement 1), S11-S24. https://doi.org/10.2337/dc17-S005.

26. Anekwe TD, Rahkovsky I. (2018). Self-Management: A Comprehensive Approach to Management of Chronic Conditions. Am J Public Health, 108(S6), S430-S436. https://doi.org/10.2105/AJPH.2014.302041r.

27. Abbott A, Malik A, van Ross R, Kulkarni J, Boulton J. Prevalence and characteristics of painful diabetic neuropathy in a large community-based diabetic population in the UK. Diabetes Care. 2011;34(10):2220-4. https://doi.org/10.2337/dc11-1108.

28. Van Acker, K., Bouhassira, D., De Bacquer, D., Weiss, S., Matthys, K., Raemen, H.,... Colin, I. M. (2009). Prevalence and impact on quality of life of peripheral neuropathy with or without neuropathic pain in type 1 and type 2 diabetic patients attending hospital outpatients clinics. Diabetes \& metabolism, 35(3), 206-213. https://doi.org/10.1016/j.diabet.2008.11.004.

29. Bouhassira D, Letanoux M, Hartemann A. (2013). Chronic pain with neuropathic characteristics in diabetic patients: a French cross-sectional study. PLoS One, 8(9). doi:10.1371/journal.pone.0074195.

30. Davies M, Brophy S, Williams R, Taylor A. The prevalence, severity, and impact of painful diabetic peripheral neuropathy in type 2 diabetes. Diabetes Care. 2006;29(7):1518-22. https://doi.org/10.2337/dc05-2228.

31. Jacovides A, Bogoshi M, Distiller LA, Mahgoub EY, Omar MK, Tarek IA, Wajsbrot DB. (2014). An epidemiological study to assess the prevalence of diabetic peripheral neuropathic pain among adults with diabetes attending private and institutional outpatient clinics in South Africa. J Int Med Res, 0300060514525759. https://doi.org/10.1177/0300060514525759.

32. Rasoul AM, Jalali R, Abdi A, Salari N, Rahimi M, Mohammadi M. The effect of self-management education through weblogs on the quality of life of diabetic patients. BMC Med Inf Decis Mak. 2019;19(1):205. https://doi.org/10.1186/s12911-019-0941-6.

33. Wattana C, Srisuphan W, Pothiban L, Upchurch SL. Effects of a diabetes self-management program on glycemic control, coronary heart disease risk, and quality of life among Thai patients with type 2 diabetes. Nurs Health Sci. 2007;9(2):135-41. https://doi.org/10.1111/j.1442-2018.2007.00315.x.

34. Jiang X, Wang J, Lu Y, Jiang H, Li M. Self-efficacy-focused education in persons with diabetes: a systematic review and meta-analysis. Psychology research behavior management. 2019;12:67.

doi:10.2147/PRBM.S192571. 
35. Didarloo AR, Shojaeizadeh D, Asl RG, Habibzadeh H, Niknami S, Pourali R. (2012). Prediction of selfmanagement behavior among Iranian women with type 2 diabetes: application of the theory of reasoned action along with self-efficacy (etra). Iranian Red Crescent Medical Journal, 14(2), 86. PMID: 22737561.

36. Grey M, Whittemore R, Jeon S, Murphy K, Faulkner MS, Delamater A, TeenCope Study Group. Internet psychoeducation programs improve outcomes in youth with type 1 diabetes. Diabetes Care. 2013;36(9):2475-82. https://doi.org/10.2337/dc12-2199.

37. Aghamolaei T, Eftekhar H, Mohammad K, Nakhjavani M, Shojaeizadeh D, Ghofranipour F, Safa O. (2005). Effects of a health education program on behavior, $\mathrm{HbA} 1 \mathrm{c}$ and health-related quality of life in diabetic patients. Acta Medica Iranica, 89-94.

38. Marks R, Allegrante JP. A review and synthesis of research evidence for self-efficacy-enhancing interventions for reducing chronic disability: implications for health education practice (part II). Health Promot Pract. 2005;6(2):148-56. https://doi.org/10.1177/1524839904266792.

39. Mokabel FM, Aboulazm SF, Hassan HE, Al-Qahtani MF, Alrashedi SF, Zainuddin FA. The efficacy of a diabetic educational program and predictors of compliance of patients with noninsulin-dependent (type 2) diabetes mellitus in Al-Khobar, Saudi Arabia. J Fam Commun Med. 2017;24(3):164. doi:10.4103/jfcm.JFCM_45_16.

40. Wu SF. (2007). Effectiveness of self-management for persons with type 2 diabetes following the implementation of a self-efficacy enhancing intervention program in Taiwan (Doctoral dissertation, Queensland University of Technology).

\section{Tables}

Table 1. The self-efficacy behaviors of the participants in preeducational evaluation $(n=72)$. 


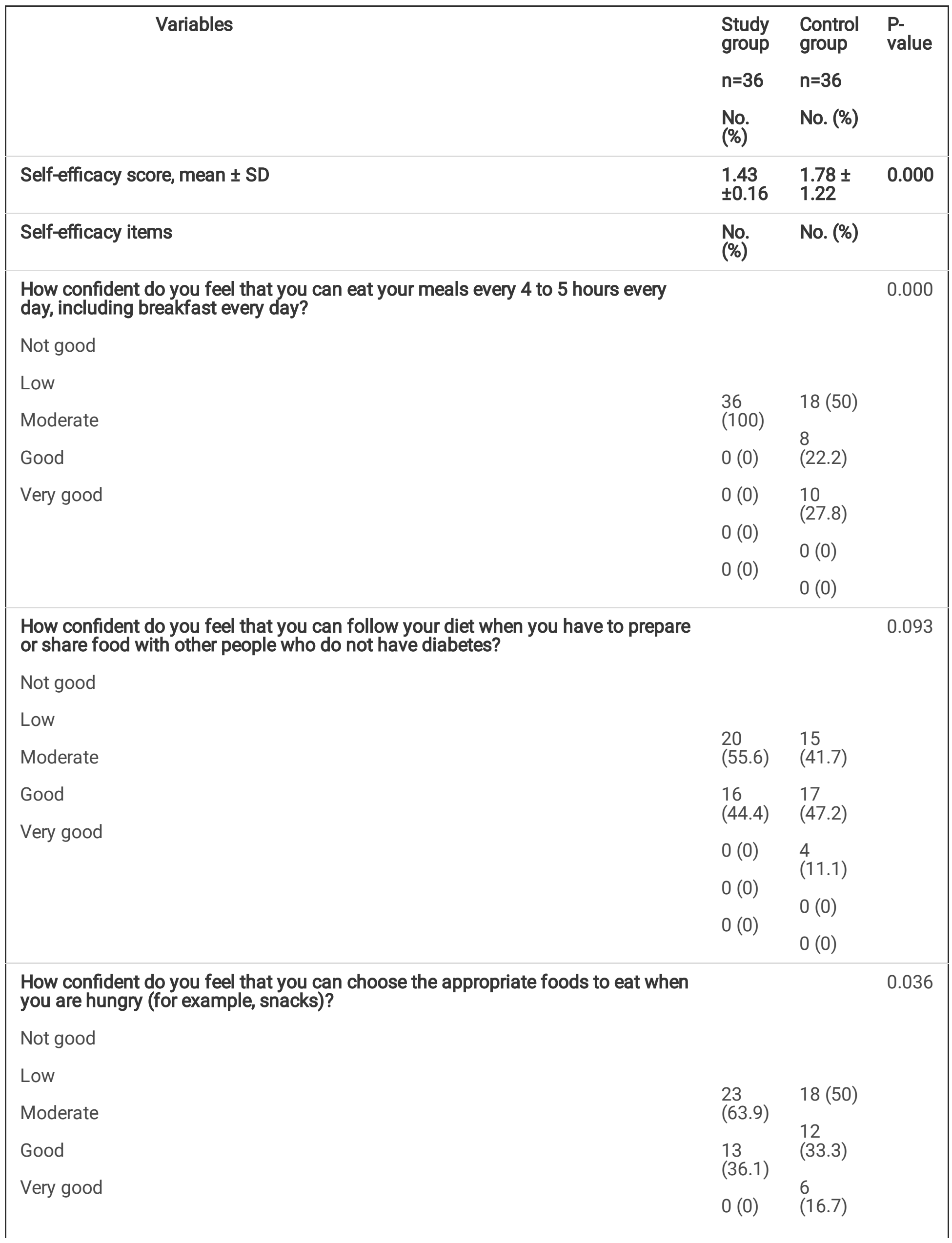


0 (0) $\quad 0(0)$

$0(0) \quad 0(0)$

How confident do you feel that you can exercise 15 to 30 minutes, 4 to 5 times a week?

Not good

Low

$36 \quad 16$

(100) (44.4)

Moderate

$0(0) \quad 13$

Good

$0(0)$

Very good

0 (0) (19.4)

$0(0) \quad 0(0)$

$0(0)$

How confident do you feel that you can do something to prevent your blood sugar level from dropping when you exercise?

Not good

Low

Moderate

25

(69.4)

11

(30.6)

$0(0) \quad 3(8.3)$

$0(0) \quad 0(0)$

$0(0) \quad 0(0)$

How confident do you feel that you know what to do when your blood sugar level goes higher or lower than it should be?

Not good

Low

Moderate

$17 \quad 14$

Good

(47.2) (38.9)

Very good

$19 \quad 10$
mean you should visit the doctor?

Not good

Low 
Moderate

Good

Very good
$3 \quad 17$
(8.3) (47.2)
$17 \quad 12$
(47.2) (33.3)
$\begin{array}{ll}16 & 7 \\ (44.4) & (19.4)\end{array}$
$0(0) \quad 0(0)$
$0(0) \quad 0(0)$

How confident do you feel that you can control your diabetes so that it does not interfere with the things you want to do?

Not good

Low

Moderate

21

(58.3) (36.1)

Good

Very good

$\begin{array}{ll}15 & 10 \\ (417) & (27.8) \\ 0(0) & 13 \\ 0(0) & (36.1) \\ 0(0) & 0(0) \\ & 0(0)\end{array}$

Table 2. The self-efficacy of the study group participants in pre- and posteducational evaluations $(n=36)$ 


\begin{tabular}{|c|c|c|c|}
\hline \multirow[t]{2}{*}{ Variables } & $\begin{array}{l}\text { Pre- } \\
\text { education }\end{array}$ & $\begin{array}{l}\text { Post- } \\
\text { education }\end{array}$ & \multirow[t]{2}{*}{ P-value } \\
\hline & No. (\%) & No. (\%) & \\
\hline Self-efficacy score, mean \pm SD & $\begin{array}{l}1.43 \\
\pm 0.16\end{array}$ & $\begin{array}{l}3.46 \pm \\
0.59\end{array}$ & 0.000 \\
\hline Self-efficacy items & No. (\%) & No. (\%) & \\
\hline $\begin{array}{l}\text { How confident do you feel that you can eat your meals every } 4 \text { to } 5 \text { hours } \\
\text { every day, including breakfast every day? }\end{array}$ & & & $0.000 * *$ \\
\hline \multicolumn{4}{|l|}{ Not good } \\
\hline \multicolumn{4}{|c|}{$36(100)$} \\
\hline \multirow[t]{2}{*}{ Moderate } & $36(100)$ & $2(5.6)$ & \\
\hline & $0(0)$ & $2(5.6)$ & \\
\hline Good & $0(0)$ & $17(47.2)$ & \\
\hline \multirow{2}{*}{ Very good } & $0(0)$ & $13(36.1)$ & \\
\hline & $0(0)$ & $2(5.6)$ & \\
\hline $\begin{array}{l}\text { How confident do you feel that you can follow your diet when you have to } \\
\text { prepare or share food with other people who do not have diabetes? }\end{array}$ & & & 0.000 \\
\hline \multicolumn{4}{|l|}{ Not good } \\
\hline \multicolumn{4}{|l|}{ Low } \\
\hline \multirow{2}{*}{ Moderate } & $20(55.6)$ & $1(2.8)$ & \\
\hline & $16(44.4)$ & $1(2.8)$ & \\
\hline Good & $0(0)$ & $18(50)$ & \\
\hline \multirow{2}{*}{ Very good } & $0(0)$ & $14(38.9)$ & \\
\hline & $0(0)$ & $2(5.6)$ & \\
\hline $\begin{array}{l}\text { How confident do you feel that you can choose the appropriate foods to } \\
\text { eat when you are hungry (for example, snacks)? }\end{array}$ & & & 0.000 \\
\hline \multicolumn{4}{|l|}{ Not good } \\
\hline \multicolumn{4}{|l|}{ Low } \\
\hline Moderate & $20(03.9)$ & 0 (U) & \\
\hline \multirow[t]{2}{*}{ Good } & $13(36.1)$ & $2(5.6)$ & \\
\hline & $0(0)$ & $18(50)$ & \\
\hline \multirow{2}{*}{ Very good } & $0(0)$ & $14(38.9)$ & \\
\hline & $0(0)$ & $2(5.6)$ & \\
\hline $\begin{array}{l}\text { How confident do you feel that you can exercise } 15 \text { to } 30 \text { minutes, } 4 \text { to } 5 \\
\text { times a week? }\end{array}$ & & & 0.000 \\
\hline \multicolumn{4}{|l|}{ Not good } \\
\hline Low & $0(0)$ & $5(13.9)$ & \\
\hline
\end{tabular}



Moderate
$0(0)$
$16(44.4)$
Good
$0(0)$
$12(33.3)$
Very good
$0(0)$
$2(5.6)$

How confident do you feel that you can do something to prevent your blood sugar level from dropping when you exercise?

Not good

Low

Moderate

$25(69.4) \quad 0(0)$

Good

$11(30.6) \quad 0(0)$

Very good

0 (0) $\quad 19(52.8)$

0 (0) $\quad 15(41.7)$

$0(0) \quad 2(5.6)$

How confident do you feel that you know what to do when your blood sugar level goes higher or lower than it should be?

Not good

Low

Moderate

$17(47.2) \quad 0(0)$

Good

$19(52.8) \quad 0(0)$

Very good

0 (0) $\quad 19(52.8)$

$0(0) \quad 15(41.7)$

0 (0) $\quad 2(5.6)$

How confident do you feel that you can judge when the changes in your illness mean you should visit the doctor?

Not good

Low

Moderate

3 (8.3) $\quad 0(0)$

Good

$17(47.2) \quad 0(0)$

16 (44.4) $11(30.6)$

Very good

$\begin{array}{ll}0(0) & 20(55.6) \\ 0(0) & 5(13.9)\end{array}$

How confident do you feel that you can control your diabetes so that it does not interfere with the things you want to do?

Not good

Low

Moderate

$21(58.3) \quad 0(0)$

Good 
Table 3. The Intensity of pain and quality of life of the participants in pre-educational evaluation $(n=72)$. 


\begin{tabular}{|c|c|c|c|}
\hline Variables & $\begin{array}{l}\text { Control group } \\
\text { No. (\%) }\end{array}$ & $\begin{array}{l}\text { Study group } \\
\text { No. (\%) }\end{array}$ & P-value \\
\hline NRS scores, mean \pm SD & $7.83 \pm 2.17$ & $6.5 \pm 3.3$ & $0.000 * *$ \\
\hline Mild pain $(\leq 3)$ & $0(0)$ & $0(0)$ & 0.070 \\
\hline Moderate pain (4-7) & $14(38.9)$ & $7(19.4)$ & \\
\hline Severe pain (8-10) & $22(61.1)$ & $29(80.6)$ & \\
\hline Quality of life, mean \pm SD & $3.67 \pm 0.81$ & $4.11 \pm 0.67$ & 0.000 \\
\hline Mobility, means \pm SD & $2.78 \pm 1.09$ & $3.03 \pm 0.81$ & 0.000 \\
\hline I have no problems in walking about & $0(0)$ & $1(2.8)$ & 0.010 \\
\hline I have slight problems in walking about & $10(27.8)$ & $0(0.0)$ & \\
\hline I have moderate problem in walking about & $13(36.1)$ & $5(13.9)$ & \\
\hline I have severe problems in walking about & $6(16.7)$ & $21(58.3)$ & \\
\hline I am unable to walk out & $7(19.4)$ & $9(25)$ & \\
\hline Self-care, means \pm SD & $2.42 \pm 0.94$ & $3.09 \pm 0.91$ & 0.000 \\
\hline I have no problems washing or dressing myself & $0(0)$ & $1(2.8)$ & 0.009 \\
\hline I have slight problems washing or dressing myself & $6(16.7)$ & $0(0)$ & \\
\hline I have moderate problems washing or dressing myself & $14(38.9)$ & $7(19.4)$ & \\
\hline I have severe problems washing or dressing myself & $11(30.6)$ & $15(41.7)$ & \\
\hline I am unable to wash or dress myself & $5(13.9)$ & $13(36.1)$ & \\
\hline Activity, means \pm SD & $2.86 \pm 0.80$ & $3.17 \pm 0.91$ & 0.000 \\
\hline I have no problems doing my usual activity & $0(0)$ & $1(2.8)$ & 0.125 \\
\hline I have slight problems doing my usual activity & $0(0)$ & $0(0)$ & \\
\hline I have moderate problems doing my usual activity & $14(38.9)$ & $6(16.7)$ & \\
\hline I have severe problems doing my usual activity & $13(36.1)$ & $14(38.9)$ & \\
\hline I am unable to do my usual activities & $9(25)$ & $15(41.7)$ & \\
\hline Discomfort, means \pm SD & $2.91 \pm 0.87$ & $3.42 \pm 0.77$ & 0.000 \\
\hline I have no pain or discomfort & $0(0)$ & $0(0)$ & 0.010 \\
\hline I have slight pain or discomfort & $0(0)$ & $1(2.8)$ & \\
\hline I have moderate pain or discomfort & $15(41.7)$ & $3(8.3)$ & \\
\hline I have severe pain or discomfort & $9(25)$ & $12(33.3)$ & \\
\hline I have extreme pain or discomfort & $12(33.3)$ & $20(55.6)$ & \\
\hline Depression, means \pm SD & $2.94 \pm 0.83$ & $2.89 \pm 0.92$ & 0.000 \\
\hline I am not anxious or depressed & $0(0)$ & $0(0)$ & 0.539 \\
\hline
\end{tabular}




$\begin{array}{lll}\text { I am slightly anxious or depressed } & 0(0) & 2(5.6) \\ \text { I am moderately anxious or depressed } & 13(36.1) & 11(30.6) \\ \text { I am severely anxious or depressed } & 12(33.3) & 12(33.3) \\ \text { I am extremely anxious or depressed } & 11(30.6) & 11(30.6)\end{array}$

$* *(P<0.01)$.

Table 4. The intensity of pain and quality of life of the study group participants in pre-and post-educational evaluations $(n=36)$. 


\begin{tabular}{|c|c|c|c|}
\hline Variables & $\begin{array}{l}\text { Preeducation } \\
\text { No. (\%) }\end{array}$ & $\begin{array}{l}\text { Post-education } \\
\text { No. (\%) }\end{array}$ & P-value \\
\hline NRS scores, mean \pm SD & $6.5 \pm 3.3$ & $5.1 \pm 1.5$ & 0.020 \\
\hline Mild pain $(\leq 3)$ & $0(0)$ & $8(22.2)$ & \\
\hline Moderate pain (4-7) & $7(19.4)$ & $28(77.8)$ & $0.000 * \star$ \\
\hline Severe pain $(8-10)$ & $29(80.6)$ & $0(0)$ & \\
\hline Quality of life, mean \pm SD & $4.11 \pm 0.67$ & $2.07 \pm 0.61$ & 0.000 \\
\hline Mobility, means \pm SD & $3.03 \pm 0.81$ & $1.11 \pm 0.71$ & 0.000 \\
\hline I have no problems in walking about & $1(2.8)$ & $7(19.4)$ & 0.000 \\
\hline I have slight problems in walking about & $0(0.0)$ & $18(50.0)$ & \\
\hline I have moderate problem in walking about & $5(13.9)$ & $11(30.6)$ & \\
\hline I have severe problems in walking about & $21(58.3)$ & $0(0)$ & \\
\hline I am unable to walk out & $9(25)$ & $0(0)$ & \\
\hline Self-care, means \pm SD & $3.09 \pm 0.91$ & $1.14 \pm 0.72$ & 0.000 \\
\hline I have no problems washing or dressing myself & $1(2.8)$ & $7(19.4)$ & 0.000 \\
\hline I have slight problems washing or dressing myself & $0(0)$ & $17(47.2)$ & \\
\hline I have moderate problems washing or dressing myself & $7(19.4)$ & $12(33.3)$ & \\
\hline I have severe problems washing or dressing myself & $15(41.7)$ & $0(0)$ & \\
\hline I am unable to wash or dress myself & $13(36.1)$ & $0(0)$ & \\
\hline Activity, means \pm SD & $3.17 \pm 0.91$ & $1.36 \pm 0.68$ & 0.000 \\
\hline I have no problems doing my usual activity & $1(2.8)$ & $4(11.1)$ & 0.000 \\
\hline I have slight problems doing my usual activity & $0(0)$ & $15(41.7)$ & \\
\hline I have moderate problems doing my usual activity & $6(16.7)$ & $17(47.2)$ & \\
\hline I have severe problems doing my usual activity & $14(38.9)$ & $0(0)$ & \\
\hline I am unable to do my usual activities & $15(41.7)$ & $0(0)$ & \\
\hline Discomfort, means \pm SD & $3.42 \pm 0.77$ & $1.31 \pm 0.71$ & 0.000 \\
\hline I have no pain or discomfort & $0(0)$ & $4(11.1)$ & 0.000 \\
\hline I have slight pain or discomfort & $1(2.8)$ & $18(50)$ & \\
\hline I have moderate pain or discomfort & $3(8.3)$ & $13(36.1)$ & \\
\hline I have severe pain or discomfort & $12(33.3)$ & $1(2.8)$ & \\
\hline I have extreme pain or discomfort & $20(55.6)$ & $0(0)$ & \\
\hline Depression, means \pm SD & $2.89 \pm 0.92$ & $0.44 \pm 0.61$ & 0.000 \\
\hline I am not anxious or depressed & $0(0)$ & $22(61.1)$ & 0.000 \\
\hline
\end{tabular}




\begin{tabular}{|lll|} 
I am slightly anxious or depressed & $2(5.6)$ & $12(33.3)$ \\
I am moderately anxious or depressed & $11(30.6)$ & $2(5.6)$ \\
I am severely anxious or depressed & $12(33.3)$ & $0(0)$ \\
I am extremely anxious or depressed & $11(30.6)$ & $0(0)$ \\
\hline
\end{tabular}

Table 5. Patient satisfaction in study group participants in post-educational evaluation ( $n=36)$. 


\begin{tabular}{|c|c|}
\hline Variables & $N(\%)$ \\
\hline Patient satisfaction score, mean \pm SD & $4.33 \pm 0.67$ \\
\hline \multicolumn{2}{|c|}{ Adheres to the rules of professional appearance } \\
\hline Never & $0(0)$ \\
\hline Low & $0(0)$ \\
\hline Moderate & $2(5.6)$ \\
\hline Good & $15(41.6)$ \\
\hline Very good & $19(52.8)$ \\
\hline \multicolumn{2}{|c|}{ Communicates well with teams' educational programs. } \\
\hline Never & $0(0)$ \\
\hline Low & $0(0)$ \\
\hline Moderate & $2(5.6)$ \\
\hline Good & $18(50)$ \\
\hline Very good & $16(44.4)$ \\
\hline \multicolumn{2}{|c|}{ Communicate well with patients to achieve effective learning } \\
\hline Never & $0(0)$ \\
\hline Low & $0(0)$ \\
\hline Moderate & $3(8.3)$ \\
\hline Good & $14(38.9)$ \\
\hline Very good & $19(52.8)$ \\
\hline \multicolumn{2}{|c|}{ Interacts and participates with activities to improve education } \\
\hline Never & $0(0)$ \\
\hline Low & $0(0)$ \\
\hline Moderate & $4(11.1)$ \\
\hline Good & $12(33.3)$ \\
\hline Very good & $20(55.6)$ \\
\hline \multicolumn{2}{|c|}{ Commitment to good behavior with all elements of the educational process } \\
\hline \multicolumn{2}{|l|}{ Never } \\
\hline Low & $0(0)$ \\
\hline Moderate & $0(0)$ \\
\hline Good & $3(8.3)$ \\
\hline Very good & $14(38.9)$ \\
\hline
\end{tabular}


Helps change the behavior of patients and encourages them to do so

Never

Low

Moderate

Good

Very good

$17(47.2)$

Commits to the timing, time and end of the lecture

Never

Low

Moderate

Good

Very good

$21(58.3)$

\section{Participates in the continuous development of information}

Never

Low

Moderate

Good

Very good $19(52.8)$

Communicates with the family of patients in a professional and good way

Never

Low

Moderate

Good

Very good

$20(55.5)$

He constantly develops his performance through continuous training

Never

Low

Moderate

Good

14 (38.9)

Very good

$17(47.2)$ 
Page 25/25 